\title{
Front Matter: Volume 8393
}

, "Front Matter: Volume 8393," Proc. SPIE 8393, Signal and Data Processing of Small Targets 2012, 839301 (5 June 2012); doi: 10.1117/12.970997

EPIE Event: SPIE Defense, Security, and Sensing, 2012, Baltimore, Maryland, SPIE. United States 


\title{
PROCEEDINGS OF SPIE
}

\section{Signal and Data Processing of Small Targets 2012}

\author{
Oliver E. Drummond \\ Richard D. Teichgraeber \\ Editors
}

25-27 April 2012

Baltimore, Maryland, United States

Sponsored and Published by

SPIE

Volume 8393 
The papers included in this volume were part of the technical conference cited on the cover and title page. Papers were selected and subject to review by the editors and conference program committee. Some conference presentations may not be available for publication. The papers published in these proceedings reflect the work and thoughts of the authors and are published herein as submitted. The publisher is not responsible for the validity of the information or for any outcomes resulting from reliance thereon.

Please use the following format to cite material from this book:

Author(s), "Title of Paper," in Signal and Data Processing of Small Targets 2012, edited by Oliver E. Drummond, Richard D. Teichgraeber, Proceedings of SPIE Vol. 8393 (SPIE, Bellingham, WA, 2012) Article CID Number.

ISSN 0277-786X

ISBN 9780819490711

Published by

SPIE

P.O. Box 10, Bellingham, Washington $98227-0010$ USA

Telephone +1 3606763290 (Pacific Time) · Fax +1 3606471445

SPIE.org

Copyright (c) 2012, Society of Photo-Optical Instrumentation Engineers

Copying of material in this book for internal or personal use, or for the internal or personal use of specific clients, beyond the fair use provisions granted by the U.S. Copyright Law is authorized by SPIE subject to payment of copying fees. The Transactional Reporting Service base fee for this volume is $\$ 18.00$ per article (or portion thereof), which should be paid directly to the Copyright Clearance Center (CCC), 222 Rosewood Drive, Danvers, MA 01923. Payment may also be made electronically through CCC Online at copyright.com. Other copying for republication, resale, advertising or promotion, or any form of systematic or multiple reproduction of any material in this book is prohibited except with permission in writing from the publisher. The CCC fee code is 0277-786X/12/\$18.00.

Printed in the United States of America.

Publication of record for individual papers is online in the SPIE Digital Library.

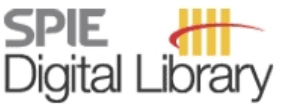

SPIEDigitalLibrary.org

Paper Numbering: Proceedings of SPIE follow an e-First publication model, with papers published first online and then in print and on CD-ROM. Papers are published as they are submitted and meet publication criteria. A unique, consistent, permanent citation identifier (CID) number is assigned to each article at the time of the first publication. Utilization of CIDs allows articles to be fully citable as soon as they are published online, and connects the same identifier to all online, print, and electronic versions of the publication. SPIE uses a six-digit CID article numbering system in which:

- The first four digits correspond to the SPIE volume number.

- The last two digits indicate publication order within the volume using a Base 36 numbering system employing both numerals and letters. These two-number sets start with 00, 01, 02, 03, 04 , 05, 06, 07, 08, 09, OA, OB ... 0Z, followed by 10-1Z, 20-2Z, etc.

The CID number appears on each page of the manuscript. The complete citation is used on the first page, and an abbreviated version on subsequent pages. Numbers in the index correspond to the last two digits of the six-digit CID number. 


\section{Contents}

vii Conference Committee
ix Introduction

\section{SIGNAL AND CHEM/BIO PROCESSING}

839303 Detecting clustered chem/bio signals in noisy sensor feeds using adaptive fusion [8393-02] S. Lundberg, C. Calderon, R. Paffenroth, Numerica Corp. (United States)

839305 Investigation of kinematic features for dismount detection and tracking [8393-04] R. Narayanaswami, A. Tyurina, D. Diel, R. K. Mehra, Scientific Systems Co., Inc. (United States); J. M. Chinn, Air Force Research Labs. (United States)

839306 VNIR data processing of small (human) targets [8393-05]

D. Rosario, U.S. Army Research Lab. (United States)

839307 Multichannel adaptive generalized detector based on parametric Rao test [8393-06]

V. Tuzlukov, Kyungpook National Univ. (Korea, Republic of)

\section{SIGNAL AND TRACK PROCESSING}

839308 A mathematical model for MIMO imaging [8393-28]

Y. Cao, J. F. Lopez, Jr., A. Martinez, Z. Qiao, The Univ. of Texas-Pan American (United States)

839309 Space-time signal processing for distributed pattern detection in sensor networks [8393-08]

R. C. Paffenroth, P. C. Du Toit, Numerica Corp. (United States); L. L. Scharf, A. P. Jayasumana,

V. Banadara, Colorado State Univ. (United States); R. Nong, Numerica Corp. (United States)

8393 OA Small curvature particle flow for nonlinear filters [8393-09]

F. Daum, J. Huang, Raytheon (United States)

8393 OC Lagrangian relaxation approaches to closed loop scheduling of track updates [8393-11]

K. A. B. White, J. L. Williams, Defence Science and Technology Organisation (Australia)

8393 OD Extrapolating target tracks [8393-12]

J. R. Van Zandt, MITRE Corp. (United States)

\section{SENSOR DATA FUSION PROCESSING}

8393 OF Particle filter tracking for long range radars [8393-32]

K. Romeo, P. Willett, Y. Bar-Shalom, Univ. of Connecticut (United States)

8393 OG PMHT for fused tracking [8393-15]

D. T. Dunham, T. L. Ogle, Vectraxx, Inc. (United States); P. K. Willett, Univ. of Connecticut (United States) 
$8393 \mathrm{OH} \quad$ Ambiguous data association and entangled attribute estimation [8393-16]

D. J. Trawick, P. C. Du Toit, R. C. Paffenroth, G. J. Norgard, Numerica Corp. (United States)

$8393 \mathrm{OI} \quad$ Measurement level AIS/radar fusion for maritime surveillance [8393-17]

B. K. Habtemariam, R. Tharmarasa, McMaster Univ. (Canada); E. Meger, exactEarth Ltd. (Canada); T. Kirubarajan, McMaster Univ. (Canada)

8393 OJ Maximum likelihood probabilistic data association (ML-PDA) tracker implemented in delay/bearing space applied to multistatic sonar data sets [8393-18]

S. Schoenecker, Naval Undersea Warfare Ctr. (United States); P. Willett, Y. Bar-Shalom, Univ. of Connecticut (United States)

$8393 \mathrm{OL}$ Information-based data prioritization in distributed tracking systems [8393-20]

N. Coult, J. N. Knight, W. Leed, S. Danford, R. Paffenroth, A. Poore, Numerica Corp. (United States)

\section{TARGET TRACK PROCESSING}

8393 OM Exploratory joint and separate tracking of geographically related time series [8393-21] B. Balasingam, P. Willett, Univ. of Connecticut (United States); G. Levchuk, J. Freeman, Aptima, Inc. (United States)

8393 ON Estimating trackability [8393-22]

J. R. Van Zandt, MITRE Corp. (United States)

839300 Prediction, tracking, and retrodiction for path-constrained targets [8393-23] K. Krishanth, R. Tharmarasa, T. Kirubarajan, McMaster Univ. (Canada); P. Valin, Defence Research and Development Canada (Canada); E. Meger, exactEarth Ltd. (Canada)

8393 OP Data modeling for nonlinear track prediction of targets through obscurations [8393-24] H. Jaenisch, Johns Hopkins Univ. (United States) and Licht Strahl Engineering Inc. (United States); J. Handley, Licht Strahl Engineering Inc. (United States)

$83930 Q \quad$ Stochastic data association in multi-target filtering [8393-25]

S. Coraluppi, C. Carthel, Compunetix Inc. (United States)

8393 OR H-PMHT for correlated targets [8393-26]

S. J. Davey, Defence Science and Technology Organisation (Australia); M. Wieneke, Univ. of Bonn (Germany); N. J. Gordon, Defence Science and Technology Organisation (Australia)

\section{SIGNAL AND DATA PROCESSING}

8393 OT Three plot correlation-based small infrared target detection in dense sun-glint environment for infrared search and track [8393-29]

S. Kim, Yeungnam Univ. (Korea, Republic of); B. Choi, Samsung Thales Co., Ltd. (Korea, Republic of); J. Kim, Agency for Defense Development (Korea, Republic of); S. Kwon, Daegu Gyeongbuk Institute of Science and Technolog (Korea, Republic of); K.-T. Kim, POSTECH (Korea, Republic of) 
8393 OU A fast coalescence-avoiding JPDAF [8393-31]

K. Romeo, D. F. Crouse, Y. Bar-Shalom, P. Willett, Univ. of Connecticut (United States)

$83930 \mathrm{~V}$ A survey of maneuvering target tracking, part VIc: approximate nonlinear density filtering in discrete time [8393-33]

X. R. Li, V.P. Jilkov, The Univ. of New Orleans (United States)

Author Index 
Proc. of SPIE Vol. $8393839301-6$

Downloaded From: https://www.spiedigitallibrary.org/conference-proceedings-of-spie on 25 Apr 2023 Terms of Use: https://www.spiedigitallibrary.org/terms-of-use 


\title{
Conference Committee
}

\author{
Symposium Chair
}

Kevin P. Meiners, Office of the Secretary of Defense (United States)

Symposium Cochair

Kenneth R. Israel, Lockheed Martin Corporation (United States)

Conference Chair

Oliver E. Drummond, Consulting Engineer (United States)

Conference Cochair

Richard D. Teichgraeber, Consulting Engineer (United States)

Program Committee

Liyi Dai, U.S. Army Research Office (United States)

Darren K. Emge, U.S. Army Edgewood Chemical Biological Center (United States)

Denise E. Jones, U.S. Army Space and Missile Defense Command (United States)

Rabinder N. Madan, Office of Naval Research (United States)

Karla K. Spriestersbach, Missile Defense Agency (United States)

Steven W. Waugh, Defense Threat Reduction Agency (United States)

Session Chairs

Signal and Chem/Bio Processing

Darren K. Emge, U.S. Army Edgewood Chemical Biological Center (United States)

Steven W. Waugh, Defense Threat Reduction Agency (United States)

Signal and Track Processing

Liyi Dai, U.S. Army Research Office (United States)

Richard D. Teichgraeber, Consulting Engineer (United States)

Sensor Data Fusion Processing

Rabinder N. Madan, Office of Naval Research (United States)

Denise E. Jones, U.S. Army Space and Missile Defense Command (United States) 
Target Track Processing

Oliver E. Drummond, Consulting Engineer (United States)

Richard D. Teichgraeber, Consulting Engineer (United States) 


\section{Introduction}

This was the $24^{\text {th }}$ in a series of SPIE conferences to focus on signal and data processing of small targets. Most SPIE conferences are concerned with processing large targets, namely, targets large enough for traditional automatic (or assisted) target recognition (ATR) with a single frame of data. A 2-D target large enough for ATR is typically larger than 100 resolution elements, for example, larger than 10 by 10 pixels. In contrast, this conference series introduced a different thrust for SPIE in 1989: processing targets smaller than 100 pixels.

This year the conference was held in Baltimore after being held in San Diego the prior year. In the future, these conferences are expected to be located in Baltimore in the spring on even years but continue to be in San Diego in the summer on odd years. The proceedings of the prior conferences in this series in 1989 through 2011 are SPIE Volumes 1096, 1305, 1481, 1698, 1954, 2235, 2561, 2759 , $3163,3373,3809,4048,4473,4728,5204,5428,5913,6236,6699,6969,7445,7698$, and 8137. A compact disk of all the papers in this series from 1989 through 2000 is available from SPIE; it is Volume 20, which is a two-disk set.

The various types of processing tasks with sensor-derived data of targets can be broadly categorized into four generic classes, as follows:

- Sensor tracking of a single (bright) target

- Image and data processing of large targets

- Signal and data processing of medium sized targets

- Signal and data processing of small targets.

Note that the size indicated in this list is in terms of the number of resolution elements or pixels. The motivation for categorizing the processing of sensor data this way is because most of the appropriate algorithms for each of these problems differ substantially from that of the others. This conference concentrates on small targets that include:

- Point source objects

- Small-extended objects

- Clusters of point source and small-extended objects or threat clouds, such as Chem/Bio threats.

The size of a typical point source target in the field of view is from less than one to about 20 pixels (resolution elements) wide, depending on the sensor design. Although the processing of point targets with data from a single sensor has been 
studied extensively, there are still many interesting challenges in this field. In contrast, the state of the art of sensor data fusion and for processing small extended-objects, clusters, and Chem/Bio clouds is far less mature, but interest is growing. The topic of Chem/Bio has been added to this conference series because the methods for tracking clusters of objects and tracking of small extended-objects may be applicable with modification. Similarly, the topic of processing for defense against cyber threats has been added because the processing methods developed for target tracking may be helpful in the cyber domain.

Small targets that are not point source objects include dismounts, small-extended objects, and unresolved closely spaced objects, sometimes called clumps. While these small targets provide little detailed information useful for ATR, they do exhibit some shape and size information that might be useful in tracking. In addition, an extended object may at times be partially or fully obscured or may obscure rather than add to the background. The apparent size and shape of a target can differ from sensor-to-sensor and over time; this may have to be taken into account. Similarly, cluster and Chem/Bio processing offers significant advantages and unique challenges since they can change in size, shape, and orientation as well as motion.

Current algorithm development is driven by new or improved sensors, increasingly demanding system requirements, efficacious countermeasures, severe operating environments, processor hardware limitations, new innovative processing methods, and challenging threat scenarios. Of special interest is the ability to track low observables or in a moderate to dense population of threshold exceedances caused by clutter, false signals, or targets that are close or crossing along with the limitation in sensor resolution.

Note that the process of algorithm development is emphasized here because Monte Carlo simulations are needed to obtain functional performance of tracking with confidence. Tracking functional performance is not amenable to mathematical analysis because it depends on random variables from both continuous sample space and discrete sample space. This property makes algorithm design, performance evaluation, and the entire algorithm development process complex and challenging. No surprise that performance results can initially appear counter intuitive.

There is an increasing need for improvements in "algorithm efficiency," i.e., improved performance relative to the processor and communication resources required. A major trade in selecting algorithms for processing small targets is performance versus required processor and communications capacity. Also needed are accurate evaluations and predictions of required resources and functional performance under realistic conditions. Major improvements are needed in: multiple target tracking, network centric sensor data fusion, multiple 
frame data association, multiple frame signal processing (such as track-beforedetect), effective management of sensors, communications, and processor resources, MHT methods use in cyber domain, target classification/typing, processing of features and attributes, efficient signal processing and tracking of Bio/Chem clouds, adaptive tracking, and the interaction between signal processing and tracking. Many of these issues are highlighted in Figure 1. In addition, there is a need for an indication of track quality and related information in the tracker output to the users and functions that depend on the tracker data to facilitate the improvement of their performance.

The term fuse-before-detect in Figure 1 refers to the combining (fusing) of raw data from multiple sensors before finalizing detection at the signal processing level. I coined this term in recognition of the increased interest in improving performance by fusing sensor data early in the processing chain. Note also in Figure 1 the possible use of track data at the signal processing level. There is a growing recognition of the importance of using all available information in every stage of the processing and hence the use of feedback.

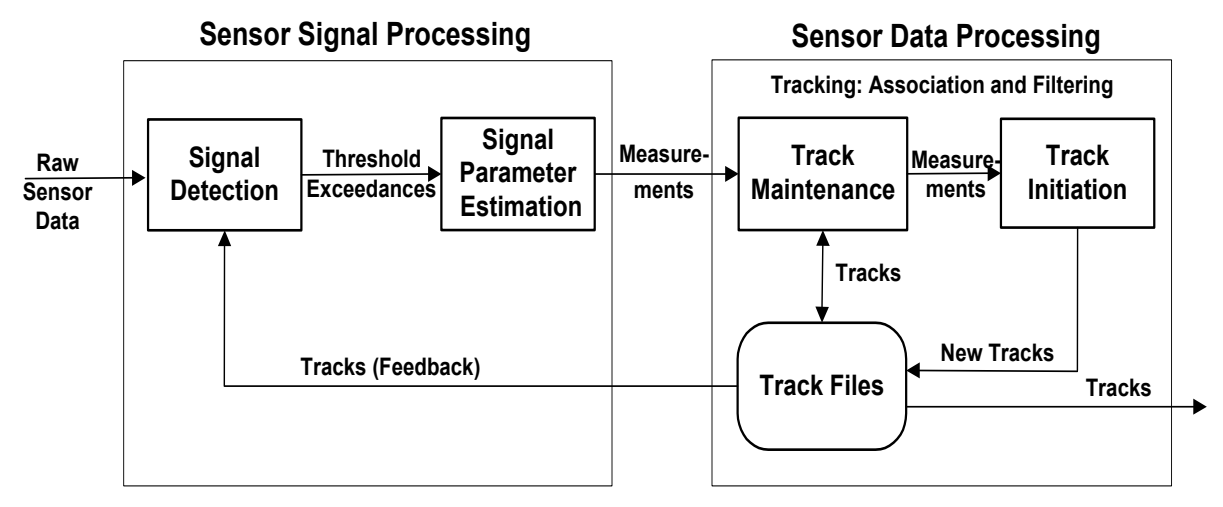

- Single-Frame Signal Processing

- Multiple-Frame Signal Processing

- Fuse Before Detect
- Single-Frame Association

- Multiple-Frame Association

- Multiple-Sensor Processing

Figure 1. Sensor Signal and Data Processing

This conference has provided a forum to address these issues through discussion of algorithms and simulations for digital signal processing, target tracking, and sensor data fusion under challenging conditions, i.e., data association (correlation) and filtering, including related data processing, such as system resource management, and target classification/typing. Of the four half-day sessions, one addressed signal-level processing including Chem/Bio cloud 
processing, two addressed target tracking and related functions, and one addressed sensor data fusion including network wide processing. The distinction between the two stages of single sensor-level processing is shown in Figure 1.

These proceedings papers contain a wealth of information that address the issues critical to practical processing under the challenging conditions outlined above. For example, important advances were presented in: processing Chem/Bio sensor data, filter methods to accommodate non-linearities, alternative multiple frame data association, improved distributed sensor data fusion, processing data of dismounts, reducing track coalescence, high fidelity simulations, and processing target features/attributes. These techniques and others presented are strong candidates to permit high performance target tracking and sensor data fusion plus related processing of low observables or in an environment of moderately dense detections and with abruptly maneuvering targets. These and other innovative yet practical techniques were presented that contribute to improving algorithm efficiency for processing small targets.

Many of the experts and organizations that are making the major important advances in practical sensor signal and data processing have contributed to these proceedings. We thank the authors, session chairs, attendees, and SPIE coordinators for making the three-day conference such a success. They have taken part in enthusiastic discussions that generated better understanding for the application of the techniques presented and have stimulated thoughts for further improvements. Informal discussions during the coffee breaks and the poster session were especially productive, as usual. With these proceedings, the authors have extended the state of the art of analysis, algorithms, and simulations for the use of data from one or more sensors used in signal and data processing of small targets and related processing.

Oliver E. Drummond, Ph.D., P.E. Consulting Engineer

Phone: 310-838-5300

E-Mail: Drummond@Att.Net Web site: http://ODrummond.com 